\title{
THERMOGRAVIMETRIC ANALYSIS, DIFFERENTIAL SCANNING CALORIMETRY AND TIME-TO-IGNITION OF WOOD MATERIALS TREATED WITH WATER GLASS FLAME RETARDANTS
}

\author{
Juraj Jancík, Linda Makovická Osvaldová \\ UNIVERSITY OF ZiLINA \\ SLOVAKIA \\ Frank Markert \\ Technical University of Denmark \\ DenMARK
}

(Received August 2020)

\begin{abstract}
The paper investigates efficiency of silicate flame retardants on wooden fibres (used for production of medium-density fibreboards) and spruce boards. A simultaneous thermal analysis and cone calorimetry were used for the assessment. Specimens were treated with three different types of silicate water glass: sodium silicate, potassium silicate and modified silicate. Along with these, one sample of untreated fibres was tested in order to provide a baseline sample. As a result of the simultaneous thermal analysis, the ability of the treatments to increase the residual amount of biological char in samples during pyrolysis and ability of the flame retardant to be retained in these wood fibres was used to assess the efficiency of each flame retardant on the wood fibres.
\end{abstract}

KEYWORDS: Simultaneous thermal analysis, cone calorimetry, time of ignition, mass loss, fibreboard, spruce, pyrolysis.

\section{INTRODUCTION}

Wood as a thermally thick construction material is widely used in various types of buildings globally. One of the weaknesses of wooden materials are the fire resistant properties, therefore, modifications to improve these properties can be beneficial. Application of flame retardants is one of the possible material modifications that is common thanks to its efficiency (Eremina et al. 2020, Gasparik et al. 2017, Lu et al. 2019, Baysal et al. 2019). 
We use water glass flame retardants for these experiments. This type of flame retardation is popular for its simple preparation and application on and into the material surface and is used not only in combination with wood materials but also with a variety of others such as coal (Fan et al. 2020) or graphite (Ustinov et al. 2017, Kasymov et al. 2019). To ensure thorough impregnation of the flame-retarding agent a vacuum/pressure impregnation is commonly used for wood materials (Lou et al. 2018, Clause et al. 2010). This was avoided in the following experiments to investigate material behavior with slender layer of flame retardant on and underneath the surface.

Testing of fire resistant properties of materials has evolved and changed through time (Makovicka Osvaldova et al. 2013, 2015) from which both rather traditional and novel methods were used, i.e. methods of cone-calorimetry and simultaneous thermal analysis (hereinafter referred to as STA). STA integrates two measurement methods, i.a. thermogravimetric analysis (hereinafter referred to as TGA) and differential scanning calorimetry (hereinafter referred to as DSC), which are widely used with wood materials (Dineff et al. 2014, Azizi et al. 2017, Grønli et al. 2002.). Results will help to assess the efficiency of silicates used as flame retardants and extend the knowledge of biochar forming in pyrolysis previously investigated by Kloss et al. (2012), Haseli et al. (2012) and Qi et al. 2016, England and Iskra (2020).

\section{MATERIALS AND METHODS}

The reaction to heat of treated hardwood and wood fibres was investigated in this paper. The density of the MDF material was about $160 \mathrm{~kg} \cdot \mathrm{m}^{-3}$. The STA was used to evaluate the effect of the different treatments. Water soluble silicates (water glass) flame retardants were used for treating: sodium silicate - type N37/40, potassium silicate - type K4009, and modified silicate - type K1530, all provided by a Danish company Bollerup Jensen A/S. Microscopic images of the samples in different phases of experiment are included accompanied by a brief commentary.

Sodium silicate (type N37/40) was marked as N (Danish: "Natron vandglas") for easier labelling of the samples that was also used during the experiment. Sodium silicate is made by melting the sand together with sodium carbonate which will end up as glass that is dissolved in water under high temperature and pressure resulting in the production of water glass. Its consistency is best described as a thick and clear liquid. The chemical formula of sodium silicate is $\mathrm{Na}_{2} \mathrm{Si}_{3} \mathrm{O}_{7}$ with a $\mathrm{pH}$ value $>12$. The density was measured to be $1.27 \mathrm{~g} \cdot \mathrm{ml}^{-1}$.

Potassium silicate (type K4009) was marked as K (Danish: "Kali vandglas"). It is a versatile inorganic chemical produced by melting sand together with potassium carbonate, dissolved in water afterwards. Potassium silicate is also thick and clear but it is easily soluble in water. It also achieves higher temperature tolerance, however it is more expensive. Chemical formula of potassium silicate is $\mathrm{K}_{2} \mathrm{Si}_{3} \mathrm{O}_{7}$ and its $\mathrm{pH}$ value is > 12 (Bollerup Jensen A/S 2016). Its density was measured at $1.24 \mathrm{~g} \cdot \mathrm{ml}^{-1}$.

Modified silicate (type K1530) will be marked as S (silica sol). It is a liquid with a mat opaque colour and sharp odour. Just like the previous silicates, it is soluble in water. Modified silicate is more expensive than the other treatments, however its lower $\mathrm{pH}$ value is favourable for wood penetration. Its $\mathrm{pH}$ value was between 3-5. Its density was measured at $1.12 \mathrm{~g} \cdot \mathrm{ml}^{-1}$.

The first of two base materials were wood fibres typically used in MDF (medium density fibreboards). These were used for the simultaneous thermal analysis. Experiments with 4 differently treated samples were conducted. One sample consisted of untreated fibres to provide the basic data for further comparison of changes with different treatments. Other three samples were treated with various types of water glass, specifically with sodium silicate (type N37/40), 
potassium silicate (type K4009) and modified silicate (type K1530). Wood materials tend to produce biochars with rather basic $\mathrm{pH}$ values in pyrolysis as indicated by Kloss et al. (2012) on spruce and poplar specimen. All densities were measured weighing $10 \mathrm{ml}$ of the treatment and scales with resolution of $0.01 \mathrm{~g}$.

Cone calorimetry was used to investigate the effect of silicate water glass flame retardants on spruce board evaluating the time to ignition at different heat fluxes $\left(20 / 25 / 30 / 40 / 50 \mathrm{~kW} \cdot \mathrm{m}^{-2}\right)$ and estimating the critical heat flux for each type of treatment, including untreated specimens. The spruce board was treated with the flame retardants by soaking under atmospheric pressure which was expected to impregnate specimens creating a thin layer on and under the surface. Pressure impregnation was not incorporated in this study.

For the cone calorimetry a specimen of spruce (Picea abies) was used. Very important property of wood is its density as it has direct impact on the flame retardant efficiency (Makovická Osvaldová et al. 2016). Average density of the spruce board was estimated to be $560 \mathrm{~kg} \cdot \mathrm{m}^{-3}$ for thickness ranging from 17 to $21 \mathrm{~mm}$. Specimens were standardly square-shaped with an exposed surface area to heat flux of $100 \mathrm{~cm}^{-2}$. Fibres and spruce specimens were treated with all the three water glass flame retardants using the same conditions. The tests include pure (untreated) spruce specimens that undergo the same procedure for further comparison of changes.

\section{Sample preparations}

Four small bowls were prepared for all treatments (pure/N/S/K). A certain amount of MDF fibres was picked for each sample and weighed afterwards to find the real weight of basic material. One gram of the agent was diluted in approximately $5 \mathrm{ml}$ of distilled water. The solution was then poured into the bowl containing fibres and stirred for approximately $5 \mathrm{~min}$ to achieve equal distribution of treatment into the entire sample. Afterwards, all the samples were inserted into a heating cabinet for a 24 hour drying process. A constant temperature of $100^{\circ} \mathrm{C} \pm 5^{\circ} \mathrm{C}$ was used. Samples were cut into finer fibres and stirred again to achieve higher homogenisation. Obviously, this whole preparation process is not necessary for the pure fibres. However, the pure sample was wetted with water and dried in the heating cabinet as well, as we wanted to keep the undergoing process equal for all tested samples. The spruce board underwent the same drying process as the fibres being exposed to $100^{\circ} \mathrm{C} \pm 5^{\circ} \mathrm{C}$ in 24 hour time span. Soaking in the water-diluted flame retardants was conducted afterwards. Specimens were soaked approximately $1 \mathrm{~cm}$ deep in flame retardant solution for $90 \mathrm{~min}$ and left for a week to dry again naturally. An optical microscope with installed camera was used to take microscopic pictures of the samples in 3 different phases of the testing, i.a. before, after STA and after furnace experiments, using the $20 \mathrm{x}$ magnification. The same samples were used for all phases of the microscopic photos. For the simultaneous thermal analysis, consisting of thermogravimetric analysis and differential scanning calorimetry, a STA 449 F3 Jupiter device manufactured by Netzsch was used. Samples were weighed with resolution of $1 \mu \mathrm{g}$. Temperature range of the measurements was set to $35-1000^{\circ} \mathrm{C}$ with heating rate set to $10 \mathrm{~K} \cdot \mathrm{min}^{-1}$. Before starting the STA temperature ramp the sample holder was evacuated. The pyrolysis atmosphere during the measurements consisted of $100 \%$ pure nitrogen. For further analysis of the results Proteus 6.1.0 software was used. Correction of TGA for phenomenon of buoyancy effect and friction force from vertically moving gas was done using TGA-BeFlat ${ }^{\circledR}$ procedure which is part of the mentioned software. 


\section{RESULTS AND DISCUSSION}

First of all, the results of thermogravimetric analysis (TGA) are shown in Fig. 1, compile all samples for clear comparison of the data. The residual masses after the pyrolysis consist of biochar from the MDF fibres and the solid residues of the silicates. In order to estimate the fractions of the biochar and the silicate residues, all samples were placed in a furnace at $950^{\circ} \mathrm{C}$ for 2 hours in air to remove the carbonized residue (biochar) of the MDF fibres. Assuming a high heat stability of the silicates, we estimated the fraction of silicate residues and thus also the ratio between these two components after the pyrolysis.

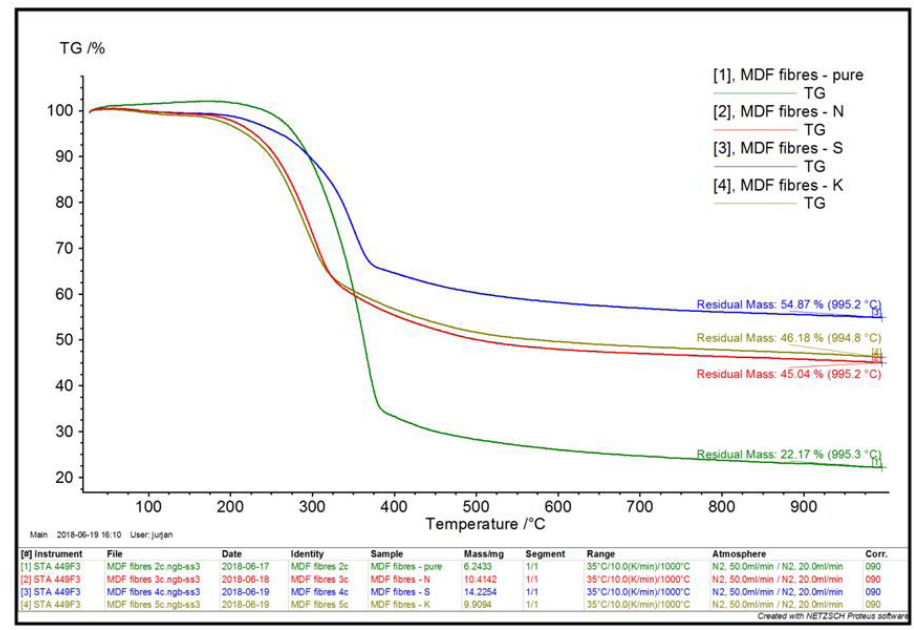

Fig. 1: Thermogravimetric analysis of the treated MDF fibres.

The results showed significant difference between treated and untreated MDF fibres as seen in Fig. 1. All the treatments (curves 2-3-4) change the pyrolysis behaviour relative to the pure MDF fibres (curve 1). Based on residual mass, modified silicate (S) achieved the best result surpassing residual mass of pure fibres by $32.7 \%$. Sodium silicate $(\mathrm{N})$ and potassium silicate $(\mathrm{K})$ show a very similar progress (curves $2-4$ ) with residual masses differing only by $1.14 \%$. Behaviour of the sodium silicate $(\mathrm{N})$ and potassium silicate $(\mathrm{K})$ samples show an interesting progress during the first third of measurement interval (Fig. 1) as they seem to initiate rapid mass loss earlier (at lower temperature) than the other samples, even relative to pure fibres. The residual masses after the pyrolysis consisted of biochar from the MDF fibres and the solid residues of the silicates. In order to estimate the fraction of the biochar, all samples were exposed to $950^{\circ} \mathrm{C}$ in a furnace for 2 hours in air and weighed afterwards (Tab. 1).

Tab. 1: Composition of samples before and after pyrolysis.

\begin{tabular}{|l|c|c|c|c|}
\hline \multicolumn{1}{|c|}{ MDF } & Pure & $+\mathbf{+ N}$ & $+\mathbf{S}$ & $+\mathbf{K}$ \\
\hline Fibres (mg) & 6.2433 & 8.6909 & 9.2824 & 7.7049 \\
\hline Treatment (mg) & - & 1.7233 & 4.943 & 2.2045 \\
\hline Biochar residue (mg)/ (\%) & $1.3841 / 22.17$ & $2.9673 / 34.14$ & $2.8625 / 30.84$ & $2.3717 / 30.78$ \\
\hline Biochar (\%)/ Treatment (\%) & - & $63.26 / 36.74$ & $36.67 / 63.33$ & $51.83 / 48.17$ \\
\hline
\end{tabular}


Biochar residue mass values are given in $\mathrm{mg}$, as shown in Tab. 1, and express the mass of the biochar in the sample after pyrolysis. The additional percentage value is its fraction in the pure fibers. The respective percentages of the biochar and the treatment are given in the bottom of Tab. 1 and are based on the mass of the STA pyrolysis measurement (Fig. 1). Comparing the biochar residue (Tab. 1) we can see that sodium silicate (N) achieved the best result from all the treatments with $34.14 \%$ residue of the former mass of fibres. Modified silicate (S) and potassium silicate $(\mathrm{K})$ acquired almost identical values of $30.84 \%$ and $30.78 \%$. The increase is evident in treatments compared to biochar residue of pure MDF fibres which acquired $22.17 \%$ residue of former mass before the pyrolysis.

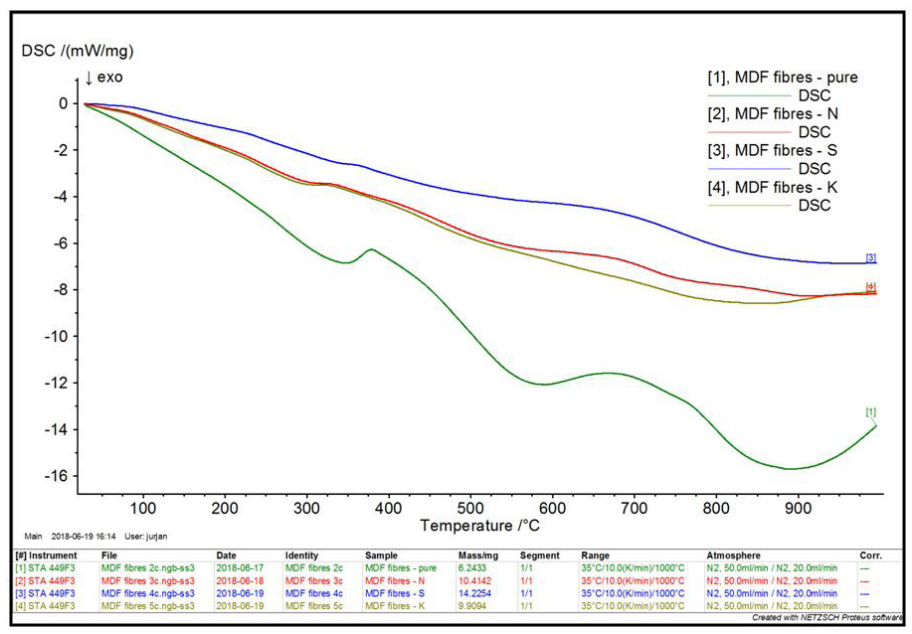

Fig. 2: Differential scanning calorimetry of the treated MDF fibres.

In addition to thermogravimetric analysis a differential scanning calorimetry (DSC) analysis was conducted and results are shown in Fig. 2. Note that the DSC results are mostly exothermic except for a signal of pure fibres where two significant parts between peaks $347.7-378.5^{\circ} \mathrm{C}$ and $590.9-668.7^{\circ} \mathrm{C}$ show the reaction is endothermic. It can be also seen at the last part of measurement on the same curve. Production of volatile by-products of the pyrolysis caused the sample to absorb energy which makes the reaction endothermic (Anca-Couce 2016). The applied treatments appear to reduce this production. Imperfection of the measuring device can influence the results as well which can be seen especially in the end of measurement on the green curve representing pure fibres. This phenomenon does not occur to such an extent in other signals where treatments moderate the progress of pyrolysis. The same samples that underwent the STA were subsequently placed in a furnace for $120 \mathrm{~min}$ at a constant temperature of $950^{\circ} \mathrm{C}$ with air atmosphere to remove the carbonized fibres (biochar) produced during the pyrolysis to find the share of biochar and treatment in sample after the STA. Microscopic images were made for the samples in 3 phases of the experiment and are shown in the Figs. 3-6. The first image was of the sample before the STA, the second image was the sample after the STA and the last one shows the sample after the furnace exposure. 


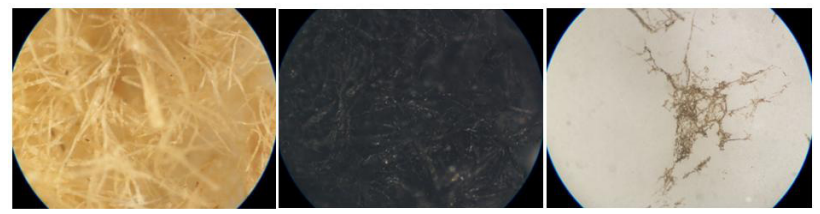

Fig. 3: Sodium silicate (N): a) original, b) after $S T A$, c) after furnace.

As we can see in the third phase (Fig. 3), there are almost no remains of fibres after the furnace exposure, demonstrating that most of it combusted completely. The amount left is negligible.

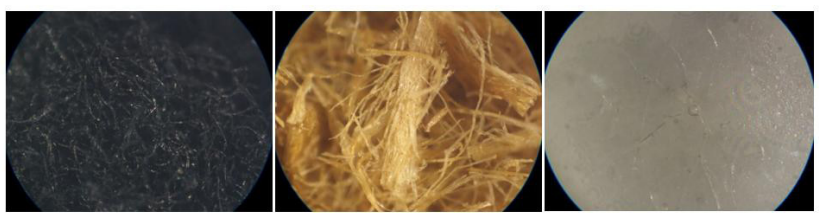

Fig. 4: Pure fibres: a) original, b) after $S T A$, c) after furnace.

Compared to pure fibres a difference in the first phase is visible (Figs. 3-4) as fibres are more bound and a colour shade appears to be a bit darker likely caused by the $\mathrm{pH}$ value of the treatment. The treatment formed a glass layer as shown at last phase of Fig. 4. There are no visible remains of fibres in the last phase.

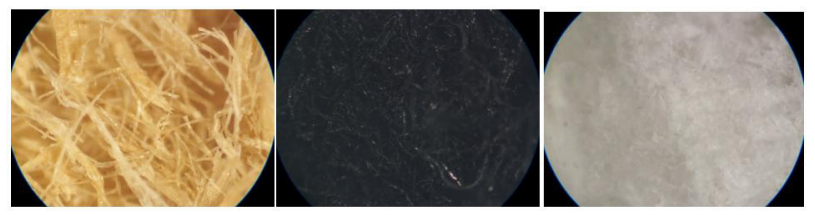

Fig. 5: Modified silicate (S): a) original, b) after STA, c) after furnace.

For the modified silicate (S) fibres in the first phase we can also see binding (Fig. 5), however the shade appears a bit brighter compared to sodium silicate $(\mathrm{N})$ in Fig. 4. The third phase shows that the treatment attained a white crystalized form.

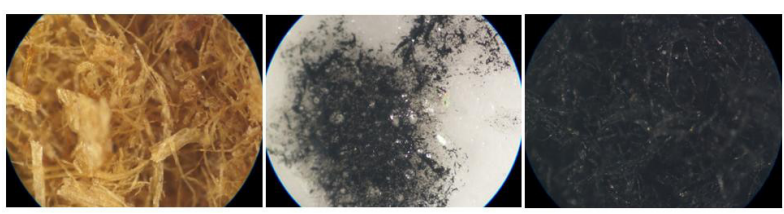

Fig. 6: Potassium silicate (K): a) original, b) after $S T A$, c) after furnace.

At the phases of potassium silicate (K) (Fig. 6) we can see similarities with phases in Fig. 4, however in the third phase of Fig. 6 a minor remains are visibly melted into the glass formed by the treatment which we should take into account for it causes a small inaccuracy in the results. Time to ignition measurements are shown in Tab. 2. The results displayed represent average value as every measurement was done twice to achieve higher precision. 
Tab. 2: Measured times of ignition of the specimens at different heat fluxes.

\begin{tabular}{|c|c|c|c|c|}
\hline Specimen & Time of ignition (s) & Specimen & Time of ignition $\mathbf{( s )}$ & $\mathbf{q e} \mathbf{e}^{\mathbf{}} \mathbf{( k W \cdot \mathbf { m } ^ { - 2 } )}$ \\
\hline Pure 1 & 137.5 & N 1 & 104 & 20 \\
\hline Pure 2 & 60 & N 2 & 55 & 25 \\
\hline Pure 3 & 51 & N 3 & 38 & 30 \\
\hline Pure 4 & 24.5 & N 4 & 23.5 & 40 \\
\hline Pure 5 & 14 & N 5 & 11 & 50 \\
\hline S 1 & 122.5 & K 1 & 103.5 & 20 \\
\hline S 2 & 68 & K 2 & 59.5 & 25 \\
\hline S 3 & 40 & K 3 & 35.5 & 30 \\
\hline S 4 & 20 & K 4 & 20.5 & 40 \\
\hline S 5 & 10.5 & K 5 & 13 & 50 \\
\hline
\end{tabular}

From the raw data we can see that untreated specimens exhibited the longest time to ignition in general, while treatments seem to reduce it. Ignition delay time $1 / \mathrm{tig}^{1 / 2}\left(1 / \mathrm{s}^{1 / 2}\right)$ is calculated according to Eq. 1 for thermal thick behavior where $k \rho c$ is thermal inertia, $q e^{\prime \prime}$ is incident heat flux, Tig is temperature of ignition and $T O$ is the ambient temperature which was measured to be $25^{\circ} \mathrm{C}$.

$$
\frac{1}{\sqrt{t_{i g}}}=\frac{2}{\sqrt{\pi} \sqrt{k \rho c}} \frac{q_{e}^{\prime \prime}}{\left(T_{i g}-T_{0}\right)}
$$

These results are displayed in Fig. 7 and for a more detailed insight also in Tab. 3 with all the source data included. Along with the ignition delay time the critical heat flux q0ig" is estimated. For the description of deviation of results a standard deviation and standard error are evaluated.

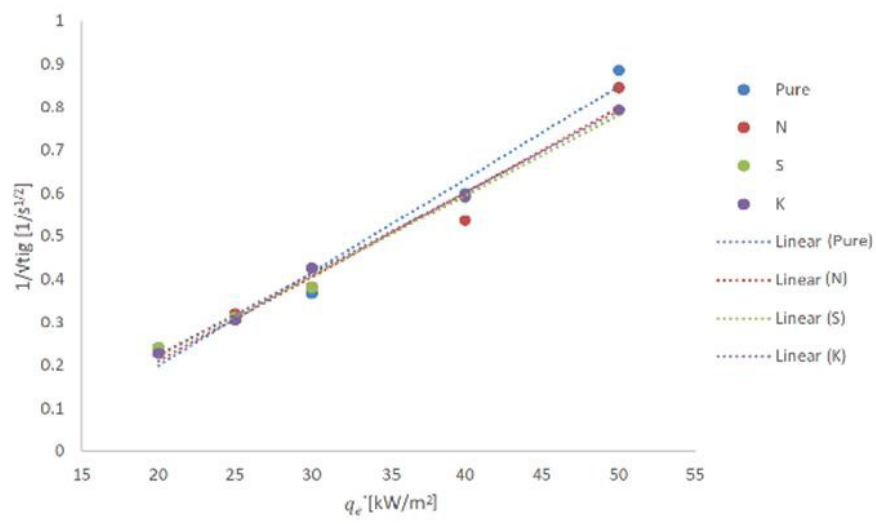

Fig. 7: Ignition delay time for different heat fluxes. 
Tab. 3: Ignition delay time, critical heat flux and standard deviation of critical heat flux.

\begin{tabular}{|c|c|c|c|c|}
\hline Specimen & $1 / ل_{\text {tig }}\left(1 / s^{1 / 2}\right)$ & Specimen & $1 / \sqrt{ }_{\operatorname{tig}}(1 / \mathrm{s} 1 / 2)$ & $q_{e} "\left(\mathrm{~kW} \cdot \mathrm{m}^{-2}\right)$ \\
\hline Pure 1 & 0.241 & N 1 & 0.236 & 20 \\
\hline Pure 2 & 0.309 & N 2 & 0.320 & 25 \\
\hline Pure 3 & 0.368 & N 3 & 0.382 & 30 \\
\hline Pure 4 & 0.600 & $\mathrm{~N} 4$ & 0.537 & 40 \\
\hline Pure 5 & 0.886 & N 5 & 0.846 & 50 \\
\hline Slope & $0.022 \pm 0.002$ & Slope & $0.0196 \pm 0.002$ & - \\
\hline Intercept & $-0.23 \pm 0.07$ & Intercept & $-0.18 \pm 0.07$ & - \\
\hline $\mathbf{R}^{2}$ & 0.977 & $\mathbf{R}^{2}$ & 0.966 & - \\
\hline q0ig" $\left(\mathrm{kW} \cdot \mathrm{m}^{-2}\right)$ & $11 \pm 3$ & q0ig" $\left(\mathrm{kW} \cdot \mathrm{m}^{-2}\right)$ & $9 \pm 4$ & - \\
\hline Specimen & $1 / ل_{\text {tig }}\left(1 / s^{1 / 2}\right)$ & Specimen & $1 / \sqrt{ }_{\operatorname{tig}\left(1 / \mathbf{s}^{1 / 2}\right)}$ & $q_{e}{ }^{\prime \prime}\left(\mathrm{kW} \cdot \mathrm{m}^{-2}\right)$ \\
\hline S 1 & 0.240 & K 1 & 0.228 & 20 \\
\hline $\mathrm{S} 2$ & 0.313 & K 2 & 0.305 & 25 \\
\hline S 3 & 0.382 & K 3 & 0.427 & 30 \\
\hline S 4 & 0.591 & K 4 & 0.594 & 40 \\
\hline S 5 & 0.792 & K 5 & 0.794 & 50 \\
\hline Slope & $0.0187 \pm 0.0008$ & Slope & $0.0189 \pm 0.0005$ & - \\
\hline Intercept & $-0.15 \pm 0.07$ & Intercept & $-0.16 \pm 0.02$ & - \\
\hline R2 & 0.994 & R2 & 0.998 & - \\
\hline q0ig" $\left(\mathrm{kW} \cdot \mathrm{m}^{-2}\right)$ & $8 \pm 2$ & q0ig" $\left(k W \cdot m^{-2}\right)$ & $8 \pm 1$ & - \\
\hline
\end{tabular}

The estimates of the critical heat flux q0ig" have shown that pure specimens achieve value of $11 \pm 3 \mathrm{~kW} \cdot \mathrm{m}^{-2}$ which roughly corresponds to critical heat flux of wood in general. Different types of wood achieve values around $12 \mathrm{~kW} \cdot \mathrm{m}^{-2}$. A decrease to $9 \pm 4,8 \pm 2$ and $8 \pm 1 \mathrm{~kW} \cdot \mathrm{m}^{-2}$ in treated specimens seems odd as it appears to be counter-intuitive yet it matches the trending data when compared. Results of all of the measurements appear to be very similar which can be clearly seen visualized in Fig. 7. A gap of $2-3 \mathrm{~kW} \cdot \mathrm{m}^{-2}$ is minor, however should not be caused by error as standard deviations and standard errors of every type of treatment are almost identical, which means that no extreme values interfering data appeared or appeared equally in all measurements. Specimens were cut in half after the experiments conducted using cone calorimeter in order to investigate carbonized layer. Captures of specimens that were exposed to $50 \mathrm{~kW} \cdot \mathrm{m}^{-2}$ heat flux are shown in Fig. 8.

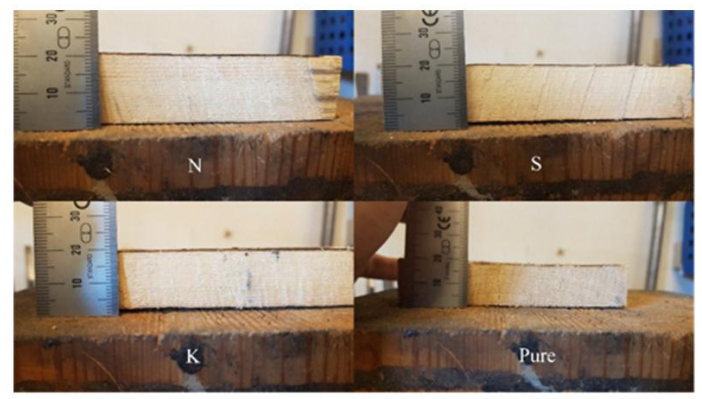

Fig. 8: Carbonized layer of spruce specimens $-50 \mathrm{~kW} \cdot \mathrm{m}^{-2}$ heat flux. 
Approximately, a $0.5 \mathrm{~mm}$ thick carbonized layer occurred in all of the treated specimens. This, however, does not apply to the pure sample where carbonization occurred solely on the surface in significantly lesser extent. Furthermore, the pure specimen exhibited the longest time to ignition (Tab. 2a). It appears that small amount of these water glass flame retardants applied with thin impregnation layer accelerated the process of carbonization at high heat flux rates. This phenomenon did not occur in samples exposed to a lower heat flux of $20 \mathrm{~kW} \cdot \mathrm{m}^{-2}$, where the carbonized layer thickness occurred equally in all of the tested specimens. Increased carbonization in spruce specimens after usage of mono-ammonium phosphate flame retardant was also reported by (Hagen et al. 2009) as we as for many other flame retarding agents as reported by (Schaffer 1974) and (Nussbaum 1988). The surface temperature at ignition varied from 240 to $271^{\circ} \mathrm{C}$ in these specimens at $50 \mathrm{~kW} \cdot \mathrm{m}^{-2}$ heat flux, which is on the edge of onset temperatures range for pyrolysis of lignin $\left(227-550^{\circ} \mathrm{C}\right.$ ) (Tan et al. 2006), cellulose $\left(250-350^{\circ} \mathrm{C}\right.$ ) (Yeng et al. 2015) and hemicellulose $\left(220-315^{\circ} \mathrm{C}\right)$ (Yang et al. 2007). It could also be that other organic compounds may help create the flammable mixture over the surface. So called extractives are common organic compounds found in wood, however their content in spruce wood reaches around $2 \%$ (Hillis 1971, Shebani et al. 2008). Their possible contribution to a flammable mixture creation in influential extent was therefore highly questionable and improbable. It is important to note that it was not a question of determining the course and development of the charred layer, but the final value after the end of the experiment. All measurements were in the same time interval.

\section{CONCLUSIONS}

The results of this experiment have shown the differences between tested treatments including no treatments. All of them have proved to have a significant effect on the pyrolysis of MDF fibres. According to biochar residue, sodium silicate $(\mathrm{N})$ has shown the best results acquiring $34.14 \%$ of the former fibre mass of the sample. This is an interesting finding from the commercial point of view as it is the cheapest of the evaluated treatments and it improves also other properties of wood such as hardness, bending strength etc. (Ming-Li et al. 2019). Sample of MDF fibres treated with modified silicate (S) achieved the best results in thermogravimetric analysis (Fig. 1) with $54.87 \%$ of residual mass, however most of this residue (63.33\%) consists of the treatment itself and biochar residue acquires the value of $30.84 \%$ of the former fibre mass (Tab. 1). Low $\mathrm{pH}$ value of modified silicate (S) enabled it to be retained in the MDF fibres most effectively compared to other treatments with $4.943 \mathrm{mg}$ of treatment in $9.2824 \mathrm{mg}$ of MDF fibres. Potassium silicate $(\mathrm{K})$ acquired almost identical result of biochar residue like modified silicate (S) with value of $30.78 \%$, however the share of treatment in the sample after pyrolysis was lower, achieving $48.17 \%$ which shows better efficiency at lower concentration compared to modified silicate (S). Both of these results are however outperformed by sodium silicate (N) having $36.74 \%$ share of treatment in the sample after pyrolysis and achieving best results in biochar residue as mentioned.

All three types of used water glass flame retardants show decrease in the onset temperature of pyrolysis which was also reported by (Hagen et al. 2009). The critical heat flux decrease from estimated $11 \mathrm{~kW} \cdot \mathrm{m}^{-2}$ to $9 \mathrm{~kW} \cdot \mathrm{m}^{-2}$ for sodium silicate $(\mathrm{N})$ and $8 \mathrm{~kW} \cdot \mathrm{m}^{-2}$ for modified silicate $(\mathrm{S})$ and potassium silicate $(\mathrm{K})$ is most probably caused by application method where only thin layer of flame retardant in specimens was created. Authors that used vacuum pressure impregnation for wood materials report an increase in critical heat fluxes, see e.g. (Hagen et al. 2009). Cause of this decrease in fire resistant properties of flame retarded specimens might be that low amount of 
thinly penetrated flame retardant might serve as empowering initializer of pyrolysis, as indicated before, yet failing to provide sufficient protection due to its inadequate impregnation. Another reason for the occurrence of this phenomenon might be that layer of flame retardant might obstruct the absorbed energy from cone to radiate partly back through the surface which would result in accelerated heating of the material on and under the surface accumulating heat, thus decreasing also the time to ignition. These are just hypotheses and further research is necessary in order to prove or disprove them.

\section{ACKNOWLEDGEMENTS}

The author would like to thank the Erasmus+ programme for the travelling grant enabling the stay at DTU FireLab. Also thank to the Danish company Bollerup Jensen A/S for providing the different water soluble silicates for material treatments.

This research was financially supported of the project KEGA 033ŽU-4/2019 "Integration of practical training in the study program of the rescue service".

\section{REFERENCES}

1. Anca-Couce, A., 2016: Reaction mechanisms and multi-scale modelling of lignocellulosic biomass pyrolysis. Progress in Energy and Combustion Science 53: 41-79.

2. Azizi, K., Moraveji, M.K., Najafabadi, H.A., 2017: Characteristics and kinetics study of simultaneous pyrolysis of microalgae Chlorella vulgaris, wood and polypropylene through TGA. Bioresource Technology 243: 481-491.

3. Baysal, E., Altay, C., Torkoglu, T., Toker, H., Peker, H., 2019: Impact of UV irradiance on selected parameters of Scots pine impregnated with some commonly used fire-retardants. Wood Research 64(2): 237-248.

4. Clausen, C.A., Green, F., Kartal, S.N., 2010: Weatherability and leach resistance of wood impregnated with nano-zinc oxide. Nanoscale Research Letters 5: 1464-1467.

5. England, P., Iskra, B., 2020: Australian building code change - eight-storey timber buildings. In: Wood \& Fire Safety. Pp 219-225, Proceedings of the $9^{\text {th }}$ International Conference on Wood \& Fire Safety, Springer Nature Switzerland AG.

6. Eremina, T., Kuznetsova, I., Rodionova, L., 2020: The study of various factors influencing the fire retardant efficiency of wood varnish. Proceedings of the $9^{\text {th }}$ International Conference on Wood \& Fire Safety, Springer Nature Switzerland AG, Pp 119-113.

7. Fan, Y.J., Zhao, Y.Y., Hu, X.M., Wu, M.Y., Xue, D., 2020: A novel fire prevention and control plastogel to inhibit spontaneous combustion of coal: Its characteristics and engineering applications. Fuel 263(1): 1-9.

8. Gasparik, M., Makovicka Osvaldova, L., Cekovska, H., Potucek, D., 2017: Flammability characteristics of thermally modified oak wood treated with a fire retardant. Bioresources 12: 8451-8467.

9. Grønli, M.G., Várhegyi, G., Di Blasi, C., 2002: Thermogravimetric analysis and devolatilization kinetics of wood. Industrial \& Engineering Chemistry Research 41: 4201-4208.

10. Hagen, M., Hereid, J., Delichatsios, M.A., Zhang, J., Bakirtzis, D., 2009: Flammability assessment of fire-retarded nordic spruce wood using thermogravimetric analyses and cone calorimetry. Fire Safety Journal 44(8): 1053-1066. 
11. Hillis, W., 1971: Distribution, properties and formation of some wood extractives. Wood Science and Technology 5: 272-289.

12. Kloss, S., Zehetner, F., Dellantonio, A., Hamid, R., Ottner, F., Liedtke V., Schwanninger, M., Gerzabek, M.H., Soja, G., 2012: Characterization of slow pyrolysis biochars: Effects of feedstocks and pyrolysis temperature on biochar properties. Journal of Enviromental Quality 41: 990-1000.

13. Lou, Z., Han, H., Zhou, M., Han, J., Cai, J., Huang, C., Zou, J., Zhou, X., Zhou, H., Sun, Z., 2018: Synthesis of magnetic wood with excellent and tunable electromagnetic waveabsorbing properties by a facile vacuum/pressure impregnation method. ACS Sustainable Chemistry \& Engineering 6(1): 1000-1008.

14. Lu, X., Li, Y.G., Zhou, X.F., Lei, F.H., Liu, Z.G., Wang, T., 2019: Degradation of wood fire retardant by UV assisted biomimetic oxidation over $\mathrm{Cu}([\mathrm{H} 4]$ salen) using BDE209 as a model. Wood Research 64(1): 83-96.

15. Makovicka Osvaldova, L., Osvald, A., 2013: Flame retardation of wood. Advance Materials Research (690-693): 1331-1334.

16. Makovická Osvaldová, L., Gašpercová. S., Mitrenga, P., Osvald. A., 2016: The influence of density of test specimens on the quality assessment of retarding effects of fire retardants. Wood Research 61(1): 35-42.

17. Ming-Li, L., Chun-Feng, L., Yan-Long, L., 2019: Physical and mechanical properties of modified poplar wood by heat treatment and impregnation of sodium silicate solution. Wood Research 64: 145-154.

18. Mitrenga, P., Vandličková, M., Dušková. M., 2016: Evaluation of the new fire retardants on wood by proposed testing method. Production management and engineering sciences. - Leiden; London: CRC Press/Balkema; Taylor \& Francis Group: 481-485.

19. Nussbaum, R., 1988: The effect of low concentration fire retardant impregnations on wood charring rate and char yield. Journal of Fire Sciences 6: 290-307.

20. Qi Y., Jang, J.H., Hidayat, W., Lee, A.H., Lee, S.H., Chae, H.M., Kim, N.H., 2016: Carbonization of reaction wood from Paulownia tomentosa and Pinus densiflora branch wood. Wood Science and Technology 50: 973-987.

21. Schaffer, E., 1974: Effect of fire retardant impregnations on wood charring rate. Journal of Fire and Flammability/Fire Retardant Chemistry Supplement 1: 96-109.

22. Shebani, A.N., van Reenen, A.J., Meincken, M., 2008: The effect of wood extractives on the thermal stability of different wood species. Thermochimica Acta 471(1-2): 43-50.

23. Tan, H., Wang, S., Luo, Z.-Y., Cen, K. F., 2006: Pyrolysis behaviour of cellulose, xylan and lignin. Ranliao Huaxue Xuebao/Journal of Fuel Chemistry and Technology 34: 61-65.

24. Ustinov, A., Pitukhin, E., Pitukhin, A., 2017: Research of thermal stability and fireresistance properties of the composite material "Water glass-graphite microparticles". Key Engineering Materials 744: 27-31.

25. Yang, H., Yan, R., Chen, H., Lee, D.H., Zheng, C., 2007: Characteristics of hemicellulose, cellulose and lignin pyrolysis. Fuel 86: 1781-1788.

26. Yeng, L.C., Wahit, M.U., Othman, N., 2015: Thermal and flexural properties of regenerated cellulose (RC)/ poly(3-hydroxybutyrate) (PHB) biocomposites. Jurnal Teknologi 75: 107-112.

27. Kasymov, D., Agafontsev, M., Perminov, V., Matrynov, P., 2019: Investigation of the ignition of wood structural materials (with and without fire retardant treatment) under the influence of a model fire of irregular intensity. The European Physical Journal Conferences 01/2019(196): 00038. 
Juraj Jancík*, Linda Makovická Osvaldová

UNIVERSITY OF ŽILINA

Faculty of Security Engineering

Department of Fire Engineering

I. MÁja 32

oIO 26 Z̆ILINA

Slovakia

*Corresponding author: juraj.jancik@fbi.uniza.sk

Frank Markert

Technical University of Denmark

Faculty of Civil Engineering

Department of Civil Engineering

Brovej ii 8

2800 Kongens Lyngby

DenMark 